\title{
A Ward round with Sherlock Holmes
}

\section{Harindra Karunathilake}

"Where the love of man is, there, also, is love of the art of medicine"-Hippocrates

During the morning ward rounds few weeks back, we encountered an unconscious patient who was brought by the police on the previous night. The patient was labeled as "no name" as there was no next of kin or known address was available.

During the discussion that ensued on how to trace his identity I ended up mentioning the TV series "Unforgotten" ${ }^{1}$ where identity of unknown remains of a body is methodically traced back to its owner. When confronted with diagnostic problems during the ward rounds, I have been as a habit relating to movies, TV series and detective stories often to the amusement of students and frustration of registrars.

When looked at medical diagnosis in a systematic and logical manner, it is an intellectual exercise, very much similar to detective work. ${ }^{2}$

Use of sophisticated diagnostic technologies, excessive reliance on investigations and blindly following guidelines and diagnostic algorithms have taken all the fun and curiosity out of art of diagnostic reasoning in medicine. The recent emergence of a new type doctor devoid of didactically taught basic science resulting in an "arm- chair" specialist whose conviction is that the solution to every clinical dilemma is to be found somewhere on the web has become a major threat to medicine ${ }^{3}$

A physician faced with a diagnostic problem is similar to a detective trying to solve a crime and both go through a similar process of analysis using available evidence and clues. Going through detective fiction there are so many sleuths who are masters of their craft who come out with the answers in most daring manner with deductive reasoning without missing the most trifle of details. Perry Mason, Miss Marple, Phillip Marlow, Hercule Poirot, Mike Hammer and Columbo to mention a few. Out of all, Sherlock Holmes stands out for his exceptional ability of observation and the use of observation to reach conclusions that solve the most convoluted crimes with remarkable ease. His deductive reasoning has parallels to medical diagnostic reasoning in many ways. The investigative strategies found in detective literature may provide us with some clues on how to confront some clinical problems. ${ }^{4}$ In fact, studying Sherlock Holmes's methodology may help a physician in his improving his observatory skills and diagnostic reasoning. An important part of a physician's gradual maturing into a competent clinician includes the nurturing and refining of his detective skills. ${ }^{5}$

Sherlock Holmes epitomizes the logical thinker and teaches us more about deductive reasoning than any other character, literary or real. ${ }^{6}$ if we read between the lines of Doyle's famous stories, we can learn a 
good deal about the art of medical diagnostics. ${ }^{5}$ As these stories dramatize, doctors also need detective skills. Had Sherlock Holmes not been a criminal detective, he might well have made a first-rate investigative physician.

In Medical diagnostics, deductive reasoning can be divided into four basic processes: gathering facts (history and examination), sorting facts, formulating differential diagnoses and arriving at solutions. ${ }^{2}$ In "The Sign of Four", Sherlock Holmes states that three qualities are necessary for the ideal detective: "observation, deduction and knowledge". ${ }^{3}$ Here again, we the parallel between the ideal profiles of doctors and detectives.

Sir Arthur Conan Doyle was a physician, and his character Sherlock Holmes was based on Dr. Joseph Bell, one of Doyle's professors during his time at the University of Edinburgh. His power of observation and diagnostic intuitions astonished medical students and patients alike. Even before patients uttered a word, Bell would describe their symptoms and give details of their past lives, rarely making a mistake. His skill in diagnosis was legendary, and this skill rested substantially on his acute powers of observation. ${ }^{6}$

Sir William Osler, a contemporary of Bell, also emphasized the importance of observation in his teachings and stated, "The whole art of medicine is in observation". Osler employed the method of Zadig, that of making deductions or inferences from inconspicuous features. Zadig, the hero of a 1747 Voltaire novelette of the same name is a philosopher, who possesses the unique ability to see the world around him and to grasp the significance of what he sees. Zadig's method of reasoning is to draw inferences from seemingly trivial details. With no other aids, Osler and his students attempted to learn all they could by observation alone. The sessions, as exciting as following the trail of a murderer, were thrilling experiences for the students (6).

Bell too felt that "precise and intelligent recognition and appreciation of minor differences is the real essential factor in all successful medical diagnosis." ${ }^{5}$ When we go through most of Holmes deductions this very skill of paying attention to trifle details stands out as the quality that help him solve the "case". Bell was fond of saying, "Observe carefully, deduce shrewdly, and confirm with evidence". ${ }^{6}$

In about 60 of Sherlock Holmes detective stories there are references to 68 diseases, 32 medical terms, 38 doctors, 22 drugs, 12 medical specialties, 6 hospitals and even 3 medical journals and 2 medical schools. ${ }^{4}$ Therefore, reading them is not an entirely alien subject for a "Problem Based Learned armchair googling" medical student.

In "The Speckled Band" Holmes admits, "I had come to an entirely erroneous conclusion, which shows, my dear Watson, how dangerous it always is to reason from insufficient data". Again, Holmes says "It is a capital mistake to theorize before you have all the evidence" in "A Study in Scarlet". Both times emphasize the importance of gathering all the facts before coming to conclusions. Very much compatible with medical diagnostic process. 
"Insensibly one begins to twist facts to suit theories, instead of theories_to_suit_facts" Holmes says in "A Scandle in Bohemia". Itsuggests that our differential diagnoses should explain gathered information, that is history and examination in medical diagnostic. "It is an old maxim of mine that when you have excluded the impossible, whatever remains, however improbable, must be the truth" is a repeatedly quoted phrase of Holmes from "The Beryl Coronet". It is true in diagnostic reasoning as well that if we approached in a systematic, logical manner, and rule out the unlikely possibilities one by one we should reach the diagnosis. ${ }^{2}$ There are many quotes from Holmes that might make parallels in clinical diagnosis and criminal deductions. $^{8}$

Medical diagnostic problems can never be taken as simple crimes to be solved. Patients are living human beings with their own complexities. Holmesian deduction cannot be used as a direct paradigm to the process of diagnosis. ${ }^{3}$ Nevertheless, the similarities between criminal deduction and medical diagnostic reasoning cannot be denied. When confronted with a diagnostic challenge relating it to an art form where value of observation is emphasized, may help you to look at the problem at hand with a fresh set of eyes.

\section{References}

1. https://www.pbs.org/show/unforgotten/

2. Miller L: Sherlock Holmes's methods of deductive reasoning applied to medical diagnostics West J Med 1985 Mar; 1 42:413-414

3. McCrory P "Elementary, my dear Watson" Br J Sports Med 2006;40:283-284

4. James R. A medical perspective on the adventures of Sherlock Holmes. J Med Ethics: Medical Humanities 2001;27:76-81

5. Peschel RE, PeschelE What physicians have in common with Sherlock Holmes: JournaloftheRoyalSocietyofMedicine1989 Jan 82:33-36

6. Patel SR Sherlock Holmes and the Case of the Vanishing Examination. Am J Med. 2018 Nov;131(11):1270-1271.

7. Belkin BM, Neelon FA, The Art of Observation: William Osier and the Method of ZadigAnnals of Internal Medicine 1992:116; 10:863-866

8. Levine D. Revalidating Sherlock Holmes for a role in medical education. Clinical Medicine 2012, Vol 12, No 2: 146-9 